\title{
Chapter 16: Future Directions in Electronic/Digital HRM
}

\section{Mohan Thite}

\begin{abstract}
This chapter draws the book to a logical conclusion by looking back and looking ahead in terms of the evolution of HR function. It examines the latest empirical trends in emerging digital technologies, HR trends, and HR initiatives. Finally, it presents an evidence based strategic framework of Digital HR principles and strategy, in the context of external environmental demands and internal organisational configurations between people, process and technology.
\end{abstract}

\section{Learning Objectives}

- Identify different milestones in the evolution of the HR function, in terms of external environment, functional and technology focus

- Study futuristic technology trends

- Study HR technology trends and related HR initiatives

- Present a framework of Digital HR Strategy

\section{Introduction}

The US-based, the Society for HRM (SHRM), the world's largest HR professional society, features a technology section on its web site (https://www.shrm.org/ResourcesAndTools/hrtopics/technology/Pages/default.aspx $)$. The following is an illustrative list of topics that it has covered in recent times:

- Gig economy, technology changing the future of work

- AI (Artificial Intelligence) won't kill all the jobs

- Predictive assessments give companies insights into candidate potential

- EU (European Union): Covert surveillance is prohibited

- Data-Friend or Enemy?

- Office Desk Sensors Can Cause Employee Anxiety (hot desking)

- Job Seekers Are Frustrated With Automated Recruiting; High-Tech Doesn't Replace High-Touch in Recruiting: Why Traditional Methods Still Matter

- What HR Can Do About Cyberbullying in the Workplace

- Social media mistakes can cost you the job

- Public Enemy No. 1 for Employers? Careless Cloud Users

- Cybercriminals Strike ADP

- The Future of Work-Augmented Intelligence Hits HR

- Is open source HR the next big thing? 
These topics capture some of the major issues, challenges, and strategies on digital HR. While they point to promising digital technologies that can aid and augment the efficiency and effectiveness of HR service delivery, they also caution us about the challenges, such as the concerns and statutory restrictions pertaining to information security and privacy, and the ill-effects of 24/7 digital connectedness, including analysis paralysis due to information overload, increasing employee stress levels, and social isolation. Strategically aligned technology can augment employee performance but sometimes, short term technologymediated patchwork solutions can turn into long term structural problems. Most importantly, we need to be mindful of the dangers of excessive and misdirected use of technology in managing people, at the cost of long term focus and investment in people, based on trust and transparency (Thite, 2004, p. 50-67), and ignoring the importance of well-defined and aligned processes, managerial competency, intuition, and insights. In other words, 'high-tech. doesn't replace high-touch'.

As pointed out in Chapter one, in the business context, digital technologies essentially refer to intelligent processes that use continuous real time feedback in order to make constant improvement in the efficiency and effectiveness of work design, processes and outcome (Thomas, Kass and Davarzani, 2013, p.2). In the process, they directly influence and enhance customer value and organisational revenue. This means, it is not 'doing digital' but 'being digital' that is most important. This requires a fundamental change in organisational mindset and culture to be a true learning organisation, underpinned by systems thinking, personal mastery, mental models, building shared vision, and team learning (Senge, 1990).

Before undertaking any organisational change/renewal, we need to ask the 3 Big Questions:

- Where are we now: Refers to the degree of alignment between external environmental demands and internal capabilities, such as McKinsey's 7-S Framework of hard elements (strategy, structure and systems) and soft elements (shared values, skills, style, and staff).

- Where do we want to go: Refers to the future-focused organisational strategy, vision and mission, keeping in mind emerging disruptive technologies, and best-practice management trends.

- How will we get there: Refers to organisation-specific and fit-for-purpose 'implementation strategies' that are constantly monitored and fine-tuned, in line with changing environmental characteristics, demands, and responses.

To answer where we are now, we need to have a keen sense of the past and the present. Accordingly, in this chapter, we begin with the evolution of the HR function in terms of the changing environmental demands, functional focus and technology focus. To answer where do we want to go, we need to look at futuristic trends in strategic management, technology and HR. Here, 'voices from the ground' by way of data collected from practitioners by consultancy organisations can be very useful. Therefore, we will examine the survey and interview data collected by reputed management consultancy firms, including, 
- Gartner Hype Cycle for Emerging Technologies (Panetta, 2017) and the top 10 strategic technology trends for 2018 (Gartner, 2017),

- The 2017 Deloitte Global Human Capital Trends (Deloitte, 2017), and

- The Sierra-Cedar 2017-2018 HR Systems Survey (Harris and Spencer, 2017).

Finally, to answer the question, how we will get there, this chapter will present a road map in the form of an evidence-based strategic framework of Digital HR Strategy.

\section{Evolution of the HR Function}

Before we explore the future directions of HR technology and the HR function in the digital world, we need to examine the historical evolution of the HR function over the last century. This analysis would help us understand why HR has taken so long to transform from a support/administrative function to being a critical and strategic function that it is today and during this journey, how it has suffered from an identity crisis and why it has been somewhat slow in adopting technology-enabled evidence based management.

As illustrated in Table 16.1, the HR function has slowly but steadily evolved from labour welfare to personnel administration to strategic HRM (SHRM) in response to external environmental changes and in the process, its functional and technology focus have undergone similar transformation.

\section{Insert Table 16.1 about here}

Just as the external environment has evolved from being domestic and stable to being global and highly uncertain, the focus of the HR function has shifted from being passive and reactive to being strategic and proactive. Similarly, HR technology has rapidly transformed from being primitive, expensive and monolithic to being highly advanced, disruptive, agile and relatively affordable. As summarised by Cohen (2015, p.205), "HR's past is relatively long and humble. The present is both positive and challenging, and the future of HR presents the profession with opportunities and even more thought-provoking challenges".

At the same time, the world is also characterised by 'digital divide' with uneven and inequitable access to information and communication technologies between and within countries. Similarly, in many countries, industries and organisations, the HR function is still reactive and confined to administrative support role. We will discuss the implications of this unevenness in environmental, HR and technology foci towards the end of the chapter. Let us turn our attention to the key emerging technologies of the future.

\section{Futuristic Technology Trends}

Gartner Hype Cycle for Emerging Technologies (Panetta, 2017, p. 2-3) highlights three 'emerging technology mega trends', namely,

- Artificial intelligence (AI) everywhere, such as cognitive computing, machine learning, smart robots and smart workspace, that enable organisations 'to harness data 
in order to adapt to new situations and solve problems that no one has ever encountered previously',

- Transparently immersive experiences, such as augmented reality, brain-computer interface, and human augmentation, that 'introduce transparency between people, business and things' with technology becoming more human-centric, and

- Digital platforms, such as 5G, quantum computing and software-defined security, with digital businesses 'moving toward inter-connected ecosystems' and technology moving towards 'ecosystem enabling platforms'.

Further, according to Gartner (2017), the top 10 strategic technology trends for 2018 with substantial disruptive potential are:

1. Artificial Intelligence (AI) Foundation: Creating systems that learn, adapt and potentially act autonomously will be a major battleground for technology vendors through at least 2020

2. Intelligent Apps and Analytics: Over the next few years, virtually every app, application and service will incorporate some level of AI. Augmented analytics is a particularly strategic growing area which uses machine learning to automate data preparation, insight discovery and insight sharing.

3. Intelligent Things: Intelligent things are physical things that go beyond the execution of rigid programming models to exploit AI to deliver advanced behaviors and interact more naturally with their surroundings and with people (e.g. autonomous vehicles, robots and drones)

4. Digital Twin: refers to the digital representation of a real-world entity or system. Well-designed digital twins of assets have the potential to significantly improve enterprise decision making.

5. Cloud to the Edge: Refers to a computing topology in which information processing, and content collection and delivery, are placed closer to the sources of this information.

6. Conversational Platforms: Will drive the next big paradigm shift in how humans interact with the digital world. The burden of translating intent shifts from user to computer.

7. Immersive Experience: While conversational interfaces are changing how people control the digital world, virtual, augmented and mixed reality are changing the way that people perceive and interact with the digital world (e.g. video games and 360degree spherical videos)

8. Blockchain: evolving from a digital currency infrastructure into a platform for digital transformation.

9. Event Driven: Central to digital business is the idea that the business is always sensing and ready to exploit new digital business moments. Business events could be anything that is noted digitally

10. Continuous Adaptive Risk and Trust: Security infrastructure must be adaptive everywhere, to embrace the opportunity — and manage the risks - that comes delivering security that moves at the speed of digital business. 
In analysing these future-focused reports, we need to keep in mind that as pointed out by Gartner Hype Cycle for Emerging Technologies (Gartner, 2018, p.1), emerging technologies typically go through the following five key phases of a technology's life cycle:

Innovation Trigger: A potential technology breakthrough kicks things off. Early proof-ofconcept stories and media interest trigger significant publicity. Often no usable products exist and commercial viability is unproven.

Peak of Inflated Expectations: Early publicity produces a number of success stories - often accompanied by scores of failures. Some companies take action; many do not.

Trough of Disillusionment: Interest wanes as experiments and implementations fail to deliver. Producers of the technology shake out or fail. Investments continue only if the surviving providers improve their products to the satisfaction of early adopters.

Slope of Enlightenment: More instances of how the technology can benefit the enterprise start to crystallize and become more widely understood. Second- and third-generation products appear from technology providers. More enterprises fund pilots; conservative companies remain cautious.

Plateau of Productivity: Mainstream adoption starts to take off. Criteria for assessing provider viability are more clearly defined. The technology's broad market applicability and relevance are clearly paying off.

What do these trends mean for HR? In the background of the above Gartner's report, Wright (2017, p.1), quotes a technology leader as saying that “... continual changes to the workforce and technology advancements will give HR teams an overt opportunity to be strategic advisors in their organizations ... HR will play a pivotal role in aligning company culture, talent, structure and processes to make sure that businesses select the right tools for delivering the best employee digital experience".

\section{Futuristic HR Trends}

The 2017 Deloitte Global Human Capital Trends (Deloitte, 2017, p. 5-9), "identify 10 areas in which organizations will need to close the gap between the pace of change and the challenges of work and talent management":

1. Organization of the future (88\%): As organisations become more digital, they face a growing imperative to redesign themselves to move faster, adapt more quickly, learn rapidly, and embrace dynamic career demands. Leading organisations are moving past the design phase to actively build this new organisation. 
2. Careers and learning (83\%): As companies build the organisation of the future, continuous learning is critical for business success. The new rules call for a learning and development organisation that can deliver learning that is always on and always available over a range of mobile platforms.

3. Talent acquisition (81\%): Recruiting is becoming a digital experience as candidates come to expect convenience and mobile contact. Savvy recruiters will embrace new talent acquisition technologies to forge psychological and emotional connections with candidates and constantly strengthen the employment brand.

4. Employee experience (79\%): Rather than focus narrowly on employee engagement and culture, organisations are developing an integrated focus on the entire employee experience. A new marketplace of pulse feedback tools, wellness and fitness apps, and integrated employee self-service tools is helping.

5. Performance management (78\%): Across all industries and geographies, companies are reevaluating every aspect of their performance management programs, from goal setting and evaluation to incentives and rewards. They are aligning these changes to business strategy and the ongoing transformation of work.

6. Leadership (78\%): Today, as never before, organisations do not just need more strong leaders, they need a completely different kind of leader-younger, more agile, and "digitalready"

7. Digital HR (73\%): HR leaders are being pushed to take on a larger role in helping to drive the organisation to "be digital," not just "do digital." As digital management practices and agile organisation design become central to business thinking, HR is focusing on people, work, and platforms.

8. People analytics (71\%): No longer is analytics about finding interesting information and flagging it for managers: It is now becoming a business function focused on using data to understand every part of a business operation, and embedding analytics into real-time apps and the way we work.

9. Diversity and inclusion (69\%): Fairness, equity, and inclusion are now CEO level issues, but continue to be frustrating and challenging. Training and education are not working well enough. The new rules focus on experiential learning, process change, data-driven tools, transparency, and accountability.

10. The augmented workforce (63\%): Automation, cognitive computing, and crowds are paradigm-shifting forces reshaping the workforce. Organisations must experiment and implement cognitive tools, focus on retraining people to use these tools, and rethink the role of people as more and more work becomes automated. However, as Panetta (2017, p. 1) argues, "(while) human augmentation has the potential to use technology to enhance bodies and minds, (it) also raises ethical and legal questions". 


\section{HR Technology Trends \& Initiatives}

Finally, we look at the Sierra-Cedar HR Systems Survey which is arguably "a global benchmark of HR technology adoption and the value achieved from the use of these technologies, seen through the eyes of HR Information Technologists (HRIT) and Information Technologists (IT)" (Harris and Spencer, 2017, p.1). According to Sierra-Cedar 2017-2018 HR Systems Survey, the top 10 HR Technology Initiatives are:

1. Business Process Improvements and innovations (67\%)

2. HR Systems Strategy: establishes or refines an HR application strategy that supports business strategy (40\%)

3. Talent Management Applications: implement or change applications including Recruiting, Performance, Learning, Compensation, or Succession Planning (35\%)

4. Service Delivery Improvements: improve the User Experience (UX) through Employee Self Service (ESS)/ Manager Self Service (MSS) or implement portals or Help Desk solutions (34\%)

5. Business Intelligence/Workforce Metrics initiatives (19\%)

6. Systems integrations (19\%)

7. Mergers and acquisitions (17\%)

8. Workforce management (17\%)

9. Mobile enablement (17\%)

10. Social enablement $(16 \%)$

In further analysing the above initiatives, Harris and Spencer (2017, p.2-5), highlight the impact on strategy, culture and technology as below:

Strategy: Strategy has become a key issue for top Performing organizations, as well as those organizations evaluating their HR Technology environments. $40 \%$ of organizations have a major HR Systems Strategy initiative; however only $17 \%$ of organizations have a strategy for integrating HR applications. $70 \%$ of the organizations with the highest HR Talent and Business outcomes have a Risk and Security Strategy that includes HR Systems.

Culture: Data driven, talent driven, socially responsible and top performing organizations provide statistically significant insights into their unique approach to HR systems. The increasing focus on initiatives such as Diversity, Pay Equity, Employee Engagement, and Leave Policies requires organizations to take both a technical and human approach.

Technology: Currently, 50\% of organizations have at least one major HR system in a Cloud environment. HR Technology buyers have been the beneficiaries of a highly competitive HRMS market. Next generation technology is designed to inform our decisions and simplify our activities; it's meant to be invisible and ubiquitous in our lives. The line between what organizations want and what they can do may come down to Intelligent Platforms.

\section{Framework of Digital HR Strategy}

Over the last 20 years, work has become more distributed and driven by collaboration. This has resulted in "the importance of connectedness, an emphasis on modularity, less reliance on authority, and an accelerating shift from input control to output control" (Evans and 
Rodriguez-Montemayor, 2016, p. 68). The very purpose of a digital strategy is to proactively respond to external environmental demands that are constantly and sometimes radically changing, by adopting an 'outside-in perspective' as well as 'inside-out perspective' in optimally reconfiguring its internal capabilities and resources . In the context of HR, this requires organisations to ensure that there is a horizontal and vertical 'strategic alignment/fit' between the business strategy, HR or Talent Management (TM) strategy, and digital HR strategy with the external and internal environments.

Based on available research evidence (Andersson, Lanvin and Van der Heydon, 2016, p.56; Deloitte, 2017, p. 91; Lanvin and Evans, 2016; Kane, Palmer, Phillips, Kiron and Buckley, 2017, p.3; Gothelf and Seiden, 2017), this chapter proposes a framework of digital HR strategy. The strategic components and considerations underpinning the digital HR strategy are listed in Figure 16.1.

Insert Figure 16.1 about here

Let us briefly explore the key concepts and principles behind the digital HR strategy:

\section{External Influencing Factors}

Globalisation and information and communication technology (ICT) have united the world like never before. This has led to ever increasing global spread and movement of production, services, capital and talent. Accordingly, global economic competitiveness has intensified with a direct influence on national and firm competitive advantages, built primarily on innovation and creative capabilities.

In the specific context of technology, the breadth and depth of technology intensity and penetration are unevenly spread across the globe. This has implications particularly for multinational firms as their technology policies and practices have to take cognizance of technological readiness and adoption in the countries they operate. Similarly, firms in emerging economies need to be realistic about their technology agenda and ambitions.

Another important external consideration is that technologies have serious implications for national cultures, social and political freedom. For example, in many countries, governments restrict freedom of thought and expression, limiting the ability of people to freely express themselves. Their national cultures also may restrain them from exercising their rights. Further, most countries have strict laws governing information security and privacy.

In Chapter one, we discussed how ageing population and lack of e-skills and digital fluency have contributed to serious skill shortages in the labour market. While many firms may therefore want to adopt global, rather than local or regional talent sourcing policy to attract the digital workforce, government restrictions, political pressures and local employee resentment may restrict their ability to recruit foreign talent.

\section{Internal Influencing Factors}

Organisations need to develop a 'customised digital footprint' that specifically addresses the unique organisational demands, keeping in mind their strengths, weaknesses, opportunities 
and threats (SWOT). Some of the internal factors that determine the role and nature of a digital strategy are

- Organisational size: The bigger an organisation, better is likely to be its ability to deploy state of the art technologies; however, historical baggage, legacy technologies and bureaucracy may restrict its ability to successfully implement it.

- Organisational structure and complexity: As explained in Chapter Three, more the complexity and bureaucracy in the organisation, more challenging is technology adoption.

- Organisational culture: As seen in Chapter Four, agile and adaptable organisations that constantly reinvent themselves by allowing employees freedom to experiment and express themselves are more likely to be digitally mature.

- Leadership: Digital world requires leaders at all levels of the organisation to lead from the front and be visionary, inspiring, competent, capable and supportive of digital initiatives, investments and experiments.

Research by Andersson et al. (2016, p. 55) revealed that the key success factors for digital initiatives are

- A clear vision

- Support from senior leadership

- Right technology in place

- Seen as a priority

- Good planning

- Strong internal collaboration

- Strong collaboration with partners

- Appropriate level of investment

- Strong organisational capabilities

- Buy-in from the board, and

- Clear expectations of contributors

\section{Core Elements of Digital HR Strategy}

As Ulrich says in his Foreword to this book, "HR is not about HR, but about delivering value to employees, organizations, customers, investors, and communities. By understanding technology, HR professional may help shape both a business and HR digital agenda”. One of the transformative roles of HR in the digitalised learning organisation is to instil and institutionalise digitally minded and agile organisational cultures, structures, and workforce practices, such as cross-functional collaboration and risk tolerance. It should develop tomorrow's leaders who are digitally literate and mature.

Digital thinking and practice demand appropriate digital skills and competencies referred to in Chapter One, and these skills need to be developed both in-house as well as sourced from outside in an optimum combination. The talent management strategy should serve as a talent 
magnet and be capable to attract, deploy, develop, and retain top talent by addressing the unique characteristics and requirements of knowledge workers referred to before.

HR is often accused of being slow and sloppy in understanding and embracing evidence based management that harnesses the potential of digital technologies, including big data, analytics, and social media. To be true strategic business partners, HR leaders should first become what they expect the rest of the organisation to be - agile, future-focused, innovation-driven, systems thinkers, cross-functional collaborators, and curators of knowledge. While HR has been somewhat successful in using technology to automate and streamline administrative work, access information, and innovate some HR practices, such as applicant tracking system and learning management system, it should now move to the next critical phase of using technology to 'create social experiences and connections', as Ulrich recommends in his Foreword to this book.

\section{Summary}

Huselid (2011, p. 311) observes that "the world is an ever more complex and challenging place to work and live. As a consequence, the workforce, workforce management systems, and the people who design and implement them have never been more important determinants of a firm's strategic success. Indeed, at the end of the day, the only truly sustainable source of competitive advantage is talent".

Harnessing the full potential of the digital world is a long-term game and is always a work-inprogress, focusing on continuous experimentation, business process reengineering and improvement.

The final message of the book is that HRM is first and foremost about being 'people-centric' before it becomes 'business-centric and technology-centric', and as such needs to place

- People over process

- Mindset over metrics, and

- Dignity (privacy) over (intrusive) data. 


\section{Case Study: University of the Future}

$\mathrm{ABC}$ university is a forty-year old public university in Australia. By Australian standards, it is a medium-size university with 4,000 academic staff offering 200 degrees to 50,000 students, across its five campuses spread around a major Australian city. It is ranked in the top $3 \%$ of universities globally. Its vision is to be one of the most influential universities in Australia and the Asia-Pacific region.

The university recognises that Information technology (IT) is now ubiquitous within higher education, which has created both challenges and opportunities. It has led to potentially 'game changing' initiatives in higher education, such as massive open online courses (MOOCs). By leveraging on emerging technologies, it aims to gain a distinct competitive advantage in a highly competitive global knowledge economy.

Accordingly, it wants to broaden and deepen its commitment to IT to make it the very essence of the university's functions of knowledge creation, preservation, synthesis and dissemination. It believes that the innovative development, use and application of IT in research, learning and teaching could be a strategic advantage. However, it is cognizant of the fact that the emerging global digital world is about 'connection rather than location' and that innovation in university practices and processes, not IT itself, will offer strategic differentiation with its local, regional and global competitors.

To meet the challenges of the unfolding digital world, the university aims to overhaul its processes and systems to facilitate agility, connectedness, and sustainability. It also aims to put its people at the centre of the change process and wants its academic workforce to be flexible and adaptable, and undertake deliberate experimentation in the application of IT in their teaching and research. In other words, its aim is to be an agile university of the future.

\section{Case Study Questions}

- Explain how the external environment has an impact on the university's way of working.

- Explain how the university's internal environment needs to respond to external demands, in terms of McKinsey's 7-S Framework of hard elements (strategy, structure and systems) and soft elements (shared values, skills, style, and staff).

- As the Head of HR of this university, design an appropriate HR Digital Strategy in line with its external realities and strategic intent. 


\section{Debating Topic: Is managing people an art or a science?}

\section{Introduction to the Topic}

According to one blogger, "Art is reason applied without limits, geared towards an ideal and guided by the practical. Science is reason applied within a framework, geared towards the practical and guided by an ideal" (Philosophy Forums, 2017). One may argue that science deals with black and white, something that is empirically proven whereas arts deal with grey, something that is fuzzy in nature. One may also argue that art is essentially about creativity, creative freedom and experimentation, individuality and non-conformity whereas science is all about empirical reasoning based on hard data or evidence, well defined structure, stability and conformity.

\section{Arguments in Favour of 'Managing people is an art'}

- HRM is about people who do not come in one size fits all. It is the intangibility of people as an asset and fuzzy nature of managing people that makes it an art. "It requires perfection through practice, practical knowledge, creativity, personal skills etc." (Wikiversity, 2017)

- Context is paramount in the practice of people management. It's not about best practice but best fit - whatever suits the circumstances. As such there cannot be a standard set of operating procedures that can be 'prescribed'.

- The key outcomes in HRM are employee motivation, productivity, performance and engagement. What works at one time, in one place and for one set of people may not work elsewhere.

- People management is less about rational decision making and more about managing emotions (winning the hearts and minds) that cannot be easily captured, measured or managed. It requires an artistic/creative way of management than scientific way.

- Scientific management can only tap into explicit knowledge, not the hidden tacit knowledge that requires the development and harnessing of informal social networks.

\section{Arguments in Favour of 'Managing people is a science'}

- "Science is a systematic body of knowledge pertaining to a specific field of study that contains general facts which explains a phenomenon. It establishes cause and effect relationship between two or more variables and underlines the principles governing their relationship. These principles are developed through scientific method of observation and verification through testing" (Wikiversity, 2017)

- "The main reason for the inexactness of science of management is that it deals with human beings and it is very difficult to predict their behavior accurately. Since it is a social process, therefore it falls in the area of social sciences. It is a flexible science \& that is why its theories and principles may produce different results at different times and therefore it is a behaviour science" (Wikiversity, 2017)

- Evidence based management means one has to formulate and implement HR policies based on scientific data and analysis. According to Rousseau and Barends (2011, p. 221), "Evidence-based HR (EBHR) is a decision-making process combining critical thinking with use of the best available scientific evidence and business information".

- Google provides the best example of data and analytics driven people management. Its HR head, Bock (2016) explains how Google uses data and analytics to take people management decisions on hiring, employee engagement, performance and reward management based purely on scientific principles of management. 


\section{Useful References}

Bock, L. (2016). Work Rules! Insights from inside Google that will transform how you live and lead. London, UK: Hodder and Stoughton.

Boettinger, H. M. (1975). Is management really an art? Harvard Business Review, January, 1975.

Devinney, T. M. \& Donald S. Siegel, D. S. (2012). Perspectives on the Art and Science of Management Scholarship. Academy of Management Perspectives, 26(1), 6-11.

Gothelf, J. and Seiden, J. (2017). You need to manage digital projects for outcomes, not outputs. Harvard Business Review. 6 February, 2017.

Philosophy Forums (2017). Definitions of art and science. Philosophy Forums.

http://forums.philosophyforums.com/threads/definition-of-art-and-science-29402.html

Rousseau, D. M. and Barends, E. G. R. (2011), Becoming an evidence-based HR practitioner. Human Resource Management Journal, 21: 221-235

Wikiversity (2017). Talk: Is management a science or an art?

https://en.wikiversity.org/wiki/Talk:Is management a science or an art $\% 3 \mathrm{~F}$

\section{Video Learning Resources}

- The changing world of work: https://news.microsoft.com/features/the-changingworld-of-work-2/

- The responsive organisation: https://news.microsoft.com/features/the-responsiveorganization/

- Unlocking creativity: https://news.microsoft.com/features/unlocking-creativity/

- Human Resource Technology Trends for 2017:

https://www.youtube.com/watch?v=-Z sxg V9Q4

- Australian HR professionals unprepared for the future:

https://www2.deloitte.com/au/en/pages/human-capital/articles/global-human-capitaltrends-2017.html

- Future Proof: http://www.abc.net.au/4corners/future-proof-promo/7562184

\section{References}

Andersson, L., Lanvin, B. and Van der Heyden, L. (2016). Digitalisation initiatives and corporate strategies: A few implications for talent. In B. Lanvin \& P. Evans (Eds.) The global competitiveness index 2017: Talent and technology. INSEAD. PP. 51-57.

Cohen, D. J. (2015). HR past, present and future: A call for consistent practices and a focus on competencies. Human Resource Management Review, 25: 205-215.

Deloitte (2017). Rewriting the rules for the digital age: 2017 Deloitte Global Human Capital Trends. [Online] https://www2.deloitte.com/content/dam/Deloitte/us/Documents/human-capital/hc2017-global-human-capital-trends-us.pdf 
Evans, P. and Rodriguez-Montemayor, E. (2016). Are we prepared for the talent overhaul induced by technology? A GTCI research commentary. In B. Lanvin \& P. Evans (Eds.) The global competitiveness index 2017: Talent and technology. INSEAD. PP. 67-83.

Gartner (2018). Gartner Hype Cycle. [Online] https://www.gartner.com/technology/research/methodologies/hype-cycle.jsp Accessed 30 January, 2018.

Gartner (2017). Gartner Identifies the Top 10 Strategic Technology Trends for 2018. [Online] https://www.gartner.com/newsroom/id/3812063 Accessed 26 January 2018

Gothelf, J. and Seiden, J. (2017). You need to manage digital projects for outcomes, not outputs. Harvard Business Review. 6 February, 2017.

Harris, S. and Spencer, E. (2017) Sierra-Cedar 2017-2018 HR Systems Survey. [Online] https://www.sierra-cedar.com/wp-content/uploads/sites/12/2018/01/SierraCedar_2017-2018_HRSystemsSurvey WhitePaper.pdf Accessed 26 January 2018

Huselid, M. A. (2011). Celebrating 50 years: Looking back and looking forward: 50 years of human resource management. Human Resource Management, 50(3): 309-312.

Kane, G. C., Palmer, D., Phillips, A. N., Kiron, D. and Buckley, N. (2017). Achieving digital maturity. MIT Sloan Management Review and Deloitte University Press, July 2017. [Online] http://www.technologypeople.com.au/wpcontent/uploads/2017/09/Achieving-Digital-Maturity.pdf Accessed 23 January, 2018.

Lanvin, B. \& Evans, P (Eds.) (2016). The global competitiveness index 2017: Talent and technology. INSEAD.

Panetta, K. (2017). Top Trends in the Gartner Hype Cycle for Emerging Technologies, 2017. [Online] https://www.gartner.com/smarterwithgartner/top-trends-in-the-gartner-hypecycle-for-emerging-technologies-2017/ Accessed 29 January, 2018.

Senge, P. M. (1990). The Fifth Discipline. London, UK: Random House.

Thite, M. (2004). Management philosophy: Foundation of people-centric culture. In M. Thite. Managing people in the new economy. P. 50-67. New Delhi: Sage.

Thomas, R. J., Kass, A. and Davarzani, L. (2013). How digital technologies are changing the way we work. Accenture. Outlook, No. 3. [Online]

https://www.accenture.com/t00010101T000000Z w /auen/_acnmedia/Accenture/Conversion-Assets/Outlook/Documents/1/Accenture-

Outlook-How-Digital-Technologies-Are-Changing-The-Way-WeWork.ashx\#zoom $=50$ Accessed 28 January 2018.

Wright, A. (2017). Top HR technology trends for 2018. Society for HRM. [Online] https://www.shrm.org/resourcesandtools/hr-topics/technology/pages/top-hrtechnology-trends-2018.aspx Accessed 26 January 2018 
Table 16.1: Evolution of HR Function

\begin{tabular}{|c|c|}
\hline Period & State of HR Function \\
\hline Up to $1940 \mathrm{~s}$ & $\begin{array}{l}\text { Labour Welfare: } \\
\text { - Environment: Minimum government intervention. Mostly guided by } \\
\text { owner's beliefs and attitudes. Labour exploitation rife. } \\
\text { - Functional Focus: Passive; Reactive; Influenced by Taylorism (Scientific } \\
\text { principles of management) } \\
\text { - Technology Focus: Primitive. Manual record keeping }\end{array}$ \\
\hline $\begin{array}{l}1950 \text { s to } \\
1960 \text { s }\end{array}$ & $\begin{array}{l}\text { Personnel Administration \& Industrial Relations: } \\
\text { - Environment: Unprecedented economic \& job growth } \\
\text { - Functional Focus: Realisation of employee motivation \& morale; } \\
\text { Evolution of job classification \& analysis; Development of Occupational } \\
\text { Categories; Growth of trade unions } \\
\text { - Technology Focus: Technology primitive (by today's standards) and } \\
\text { costly. Advent of transactional Electronic Data Processing (EDP) using } \\
\text { mainframes }\end{array}$ \\
\hline $\begin{array}{l}\text { 1970s to } \\
1980 \mathrm{~s}\end{array}$ & $\begin{array}{l}\text { Human Resource Management: } \\
\text { - Environment: Rapid growth of labour legislation; Increasing competition } \\
\text { from Japanese manufacturers leading to cost consciousness } \\
\text { - Functional Focus: Considered a mainstream function; Increasing } \\
\text { professionalism across all HR functions; Shift in focus from employee } \\
\text { maintenance to development. } \\
\text { - Technology Focus: Increased requirements for legislative compliance \& } \\
\text { associated data; Employee record system; Technology becomes cheaper \& } \\
\text { more efficient; Advent of Management Information System (MIS) using } \\
\text { personal computers }\end{array}$ \\
\hline $\begin{array}{l}1990 \text { s to } \\
2000 \text { s }\end{array}$ & $\begin{array}{l}\text { Strategic Human Resource Management: } \\
\text { - Environment: Increasing globalisation \& competitiveness; Global } \\
\text { movement of capital, production and labour leading to business process } \\
\text { reengineering, outsourcing \& offshoring; Focus on cost reduction \& } \\
\text { productivity improvement to do 'more with less' } \\
\text { - Functional Focus: Strategic business partner \& change agent as key roles } \\
\text { for HR; Centres of expertise/excellence; Integrated talent management } \\
\text { system; Increasing pressure on HR to deliver technology-enabled HR } \\
\text { services better, faster and cheaper; Increasing adoption of flexi-labour, } \\
\text { outsourcing, self-service and shared services in HR; Increasing awareness } \\
\text { about data-driven evidence-based management of HR functions; Balanced } \\
\text { scorecard. } \\
\text { - Technology Focus: Rapid world-wide-web-enabled software advances } \\
\text { leading to Decision Support Systems (DSS); Rise of Enterprise Resource } \\
\text { Planning (ERP) with enterprise wide networking of IT infrastructure \& }\end{array}$ \\
\hline
\end{tabular}




\begin{tabular}{|l|l|}
\hline 2010 to Today & business functions. \\
& $\begin{array}{l}\text { Smart/Digital HRM: } \\
\text { - Environment: Further push for globalisation leading to hyper-competition } \\
\text { \& extremely uncertain business environment; Innovation, creativity, } \\
\text { ambidexterity (simultaneous focus on competition \& collaboration, } \\
\text { flexibility \& sustainability) \& agility as key competitive advantages; Push } \\
\text { for all-inclusive stakeholder focus, including employee well-being, societal } \\
\text { well-being \& environmental well-being. }\end{array}$ \\
$\begin{array}{l}\text { - Functional Focus: World of work becoming anytime, anywhere 24/7 } \\
\text { environment; Future-focused; Learning organisation focus in a knowledge- } \\
\text { intensive environment; Increasing need for HR business case (cost } \\
\text { justification, return on investment, gestation, utility analysis etc.) leading to } \\
\text { adoption of HR metrics \& analytics; Managing multi-generational \& highly } \\
\text { diverse workforce. }\end{array}$ \\
$\begin{array}{l}\text { - Technology Focus: Rapid introduction \& advancement of social, mobile, } \\
\text { analytics, and cloud (SMAC) technologies; Focus on apps, Artificial } \\
\text { Intelligence (AI) \& robotics; Executive Information/Support Systems } \\
\text { (EIS/ESS) for high-level prescriptive \& predictive analytics (what-if } \\
\text { scenarios); Disruptive technologies destroying old businesses and creating } \\
\text { new ones; Rapid technological obsolesce; Highly networked and connected } \\
\text { world }\end{array}$ \\
\hline
\end{tabular}

Source: Author 


\begin{tabular}{|c|c|c|}
\hline $\begin{array}{l}\text { External Influencing Factors } \\
\text { - Economic competitiveness } \\
\text { - Technological intensity \& } \\
\text { penetration (breadth and } \\
\text { depth) } \\
\text { - Social, political \& economic } \\
\text { fabric of society } \\
\text { - Labour market demand \& } \\
\text { supply } \\
\text { - Workforce demographics \& } \\
\text { digital literacy } \\
\text { - Statutory laws \& regulations } \\
\text { on information security \& } \\
\text { privacy }\end{array}$ & $\begin{array}{l}\quad \text { Digital HR Strategy } \\
\text { - Focus: Optimum leverage of people, process \& } \\
\text { technology } \\
\text { - Customise digital footprint that best suits you } \\
\text { - Develop a multi-layer HR technology architecture } \\
\text { - Develop digitally competent workforce } \\
\text { - Develop a digitally competent and confident HR team } \\
\text { - Cross-functional strategic partnership } \\
\text { - Be innovation-focused } \\
\text { - Adopt soft-systems thinking and Agile approaches } \\
\text { - Optimally leverage technology- and human-touch } \\
\text { across HR functions } \\
\text { - Conduct due diligence of HR technology products \& } \\
\text { vendors } \\
\text { - Strategically \& selectively automate \& outsource } \\
\text { - Address unintended negative consequences } \\
\text { - Benchmark \& adopt best practices } \\
\text { - Don't overdo technology. It's always people over } \\
\text { process, mindset over metrics and dignity over data }\end{array}$ & $\begin{array}{l}\text { Internal Influencing Factors } \\
\text { - Organisational vision, mission } \\
\text { \& business strategy } \\
\text { - Organisational size and } \\
\text { complexity } \\
\text { - Organisational structure \& } \\
\text { design } \\
\text { - HR/ Talent Management (TM) } \\
\text { Strategy } \\
\text { - Quality of IT assets, skills \& } \\
\text { infrastructure (legacy systems) } \\
\text { - Top management awareness } \\
\text { \& support } \\
\text { - Organisational culture } \\
\text { - Change readiness/ agility of } \\
\text { the workforce }\end{array}$ \\
\hline
\end{tabular}

